\title{
A Thermo-responsive Supramolecular Hydrogel that Senses Cholera Toxin via Color-Changing Response
}

\author{
Dipen Biswakarma, ${ }^{a}$ Nilanjan Dey ${ }^{\mathrm{a}}$ and Santanu Bhattacharya *a,b
}

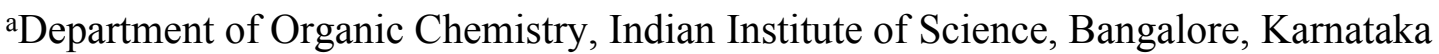
560012, India

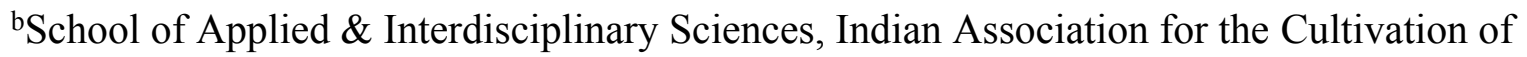
Science, Jadavpur, Kolkata 700 032, India

Email: sb@iisc.ac.in 


\section{Physical measurements and instrumentation}

Material and Methods. All chemicals, solvents and silica gel for TLC were obtained from well-known commercial sources and were used without further purification, as appropriate. Cholera Toxin was obtained from Sigma Aldrich. Solvents were distilled and dried by standard procedure before use. Melting points was measured in open capillaries and were uncorrected. ${ }^{1} \mathrm{H}-\mathrm{NMR}$ and ${ }^{13} \mathrm{C}-\mathrm{NMR}$ spectra were recorded in Bruker-400 Advance NMR spectrometer. Chemical shifts were reported in ppm downfield from the internal standard tetramethyl silane (TMS). Mass spectrometry of individual compounds was performed using a Micro Mass ESITOF MS instrument. Elemental analysis was recorded in Thermo Finnigan EA FLASH 1112 SERIES.

Gelation Studies. A detailed procedure of gelation has been discussed in the main manuscript. The formation of the gel was confirmed using the tube inversion method. If a gel was formed, it was evaluated quantitatively by determining the critical gelator concentration (CGC) which is the minimum amount of gelator required to immobilize $1 \mathrm{~mL}$ of a particular solvent or solvent mixtures. A glass tube with a capacity of $10 \times 75 \mathrm{~mm}$ has been used for the CGC measurement.

FT-IR Spectroscopy. Prepared solution and gels were drop casted on the $\mathrm{CaF}_{2}$ cell and dried under vacuum and FT-IR spectra were recorded in Perkin Elmer Spectrum BX FT-IR system. For the solid sample we have taken the powder sample and then FT-IT was recorded.

UV/Vis and Fluorescence Spectroscopy. The UV-Vis Spectroscopy and Fluorescence Spectroscopy of described solutions/suspensions were recorded on a Shimadzu model 2100 spectrophotometer and Cary-Eclipse spectrofluorimeter respectively, both equipped with a temperature controller bath.

Circular Dichroism Spectroscopy (CD). All the CD spectra of described solutions were recorded on a JASCO instrument, Model J-815-150S. Experiments were performed by purging dry $\mathrm{N}_{2}$ gas continuously. Data were collected in a quartz cuvette of $1 \mathrm{~mm}$ path length between 200 to $450 \mathrm{~nm}$.

Atomic Force Microscopy (AFM). A dilute solution of the sample was deposited on freshly cleaved mica surface and then carefully air-dried. Each of the samples was analyzed using a 
JPK 00901 AFM instrument and Nano-Wizard software. Tapping mode off $10 \mathrm{~nm}$ tip radius, silicon tip, $292 \mathrm{KHz}$ resonant frequency, 0.7-1 Hz scan speed, 256 x 256 and 512 x 512- pixels.

Transmission Electron Microscopy (TEM). A dilute solution of the aggregate at specified concentration were drop coated on carbon-coated copper grids and it was then air-dried carefully. Each sample was stained with $0.1 \%$ uranyl acetate solution and the TEM images were taken at an accelerating voltage of $200 \mathrm{kV}$ using a TECNAI F30 instrument.

Scanning Electron Microscopy (SEM). The gels or the specified solution were carefully drop casted onto the brass stubs and were allowed to air-dry overnight. The samples were then coated with gold vapor and analyzed on a Quanta 200 SEM operated at 10-15 kV.

Fluorescence Microscopy. A diluted solution of PyLac was drop casted on a pre-cleaned glass slides and it was left overnight for drying in a dust free environment and finally evacuated. The fluorescence microscopic images were taken on an Olympus IX-71 microscope with the excitation of 300-400 nm UV light.

Dynamic Light Scattering (DLS). DLS measurements were performed at room temperature using a Malvern Zetasizer Nano ZS particle sizer (Malvern Instruments Inc., Westborough, MA). Samples were prepared and examined under a dust-free conditions. Average hydrodynamic diameters $\left(D_{h}\right)$ reported were obtained from the Gaussian analysis of the intensity-weighted particle size distributions.

X-ray Diffraction. The gel sample of the specified concentration was prepared and was carefully taken on glass slide and dried under vacuum for the corresponding XRD measurement. These samples were examined using Bruker D8 Advance instrument $(\theta, 2 \theta$ geometry with Scintillation Detectors). The $\mathrm{X}$ - ray beam generated with a rotating $\mathrm{Cu}$ anode at the wavelength of KR beam at 1.5418 was directed towards the film directed toward the film edge and scanning was done up to a $2 \theta$ value of $30^{\circ}$. Data were then analyzed and interpreted using the Bragg equation.

Energy Minimization. Energy minimization of the compound was performed using B3LYP/6$31 \mathrm{G}^{*}$ level of computations.

Rheological studies. Rheology experiments of the gels were carried out using Antor Paar MCR 52 with a cone and plate geometry (CP 25-2) having an adjustable peltier temperature controlling system. The distance between the cone and plates was kept fixed at $0.105 \mathrm{~mm}$ for 
all the measurement. The gels were taken on the plate of the rheometer. An oscillatory strain amplitude sweep experiment was performed at a constant oscillation frequency of $1 \mathrm{~Hz}$ for the applied strain range $0.01-100 \%$ at $20^{\circ} \mathrm{C}$. The rheometer has inbuilt software that converts the torque measurements into either G' (the storage modulus) and G" (the loss modulus) which is represented either as strain or shear stress. Oscillatory frequency sweep experiments were performed in the linear viscoelastic region (strain $0.01 \%$ ) to ensure that calculated parameters correspond to an intact network structure.

Fluorescence-Decay Experiments. Fluorescence lifetimes were measured by using a time-correlated single-photon-counting fluorimeter (Horiba Jobin Yvon). The system was excited with nano LED light (Horiba-Jobin Yvon) with a pulse duration of 1.2 ns. (slit width: $\left.2 / 2, \lambda_{\mathrm{em}}=345 \mathrm{~nm}\right)$. The average fluorescence lifetimes $\left(\tau_{\mathrm{av}}\right)$ for the exponential iterative fitting were calculated from the decay times $\left(\tau_{\mathrm{i}}\right)$ and the relative amplitudes $\left(\alpha_{\mathrm{i}}\right)$ by using Equation (1), where $a_{1-3}$ are the relative amplitudes and $\tau_{1-3}$ are the lifetime values.

$\tau_{a v}=\left(\alpha_{1} \tau_{1}^{2}+\alpha_{2} \tau_{2}^{2}+\alpha_{3} \tau_{3}^{2}\right) /\left(\alpha_{1} \tau_{1}+\alpha_{2} \tau_{2}+\alpha_{3} \tau_{3}\right)$

Preparation of Test Strip: The paper strip $(10.5 \mathrm{~cm} \times 2 \mathrm{~cm})$ was dipped in the solution containing PyLac $(0.8 \mathrm{mM})$ for $40 \mathrm{sec}$ followed by cooling at room temperature. The remaining solvent was then completely removed under reduced pressure and the dried strip was cut into pieces and used further for the detection of CT. 

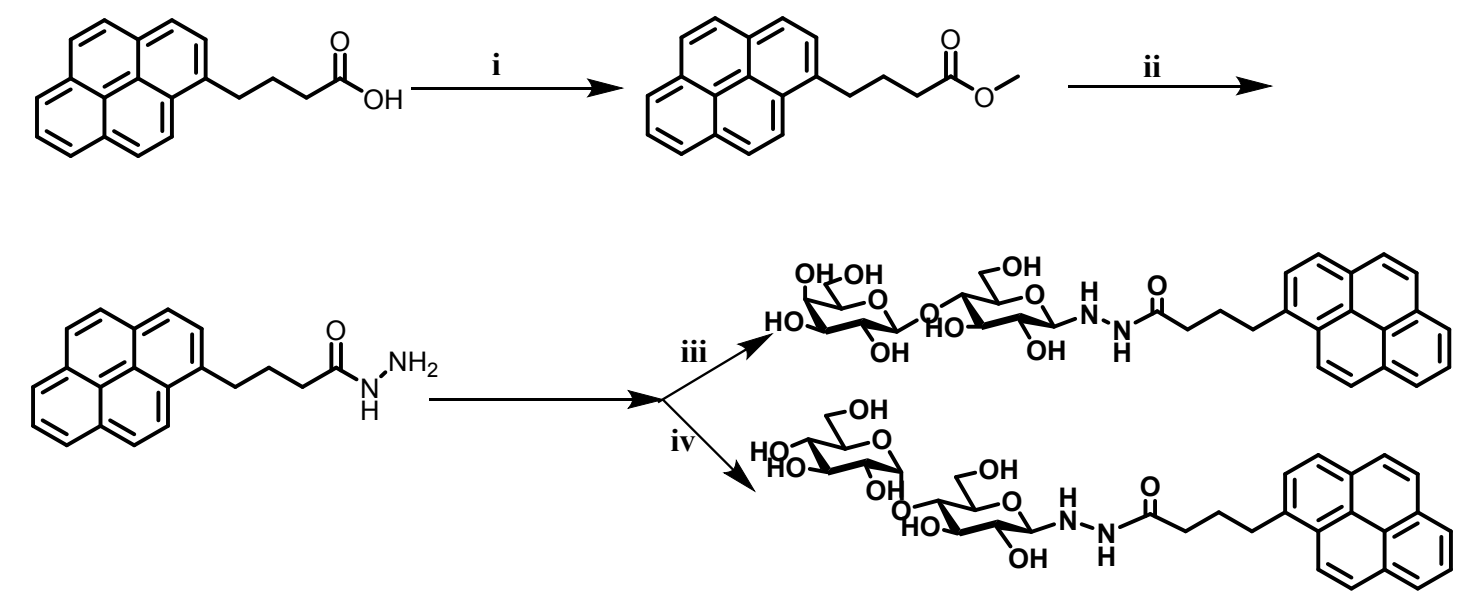

a'Reagents, Conditions and Yields. (i) $\mathrm{MeOH}$, c. $\mathrm{H}_{2} \mathrm{SO}_{4}$ (cat.), $65^{\circ} \mathrm{C}, 6 \mathrm{~h}, 98 \%$; (ii) $\mathrm{NH}_{2} \mathrm{NH}_{2} \cdot \mathrm{H}_{2} \mathrm{O}$, $\mathrm{MeOH}, 65{ }^{\circ} \mathrm{C}, 12 \mathrm{~h}, 97 \%$; (iii) D-Lactose. $\mathrm{H}_{2} \mathrm{O}, \mathrm{CHCl}_{3} / \mathrm{MeOH}(1: 3 \mathrm{v} / \mathrm{v}), 65^{\circ} \mathrm{C}, 36 \mathrm{~h}, 65 \%$; (iv) DMaltose. $\mathrm{H}_{2} \mathrm{O}, \mathrm{CHCl}_{3} / \mathrm{MeOH}(1: 3 \mathrm{v} / \mathrm{v}), 65^{\circ} \mathrm{C}, 36 \mathrm{~h}, 69 \%$.

Synthetic procedure and characterization: The synthesis of $\mathbf{2}$ and $\mathbf{3}$ were carried out following the procedures reported in the literature. ${ }^{\text {Sa-c }}$

Synthesis of PyLac. 4-(pyren-1-yl) butanehydrazide (1 g, $3.47 \mathrm{mmol}$ ) and D-lactose monohydrate $(1.6 \mathrm{~g}, 4.20 \mathrm{mmol})$ were taken in a round bottom flask. The mixture was dissolved by adding $35 \mathrm{~mL}$ of $\mathrm{MeOH} / \mathrm{CHCl}_{3}(3: 1 \mathrm{v} / \mathrm{v})$ to it and refluxed at $65^{\circ} \mathrm{C}$ for $24 \mathrm{~h}$. The resultant mixture was cooled, and the solvent was evaporated in vacuum or under reduced pressure to afford an off- white residue. The residue so obtained was purified by repetitively washing with chloroform and water. The resultant residue was vacuum dried to get a white solid product with $65 \%$ isolated yield. M.P. $\left(170{ }^{\circ} \mathrm{C}\right)$ FT-IR $\left(\mathrm{KBr} \mathrm{cm}^{-1}\right)$ 3414, 3298, 3064, 2871, 1654, 1527 , 1459, 1302.26, 1120, 1081; ${ }^{1} \mathrm{H}$ NMR (400 MHz, DMSO-d $\left.{ }_{6}\right) \delta 1.98-2.00$ (m, 2H), 2.17-2.26 $(\mathrm{m}, 2 \mathrm{H}), 3.01-3.06(\mathrm{~m}, 1 \mathrm{H}), 3.26-3.29(\mathrm{~m}, 5 \mathrm{H}), 3.34(\mathrm{~m}, 1 \mathrm{H}), 3.36(\mathrm{~m}, 2 \mathrm{H}), 3.49(\mathrm{~m}, 2 \mathrm{H}), 3.60$ $(\mathrm{m}, 3 \mathrm{H}), 4.15-4.17(\mathrm{~m}, 2 \mathrm{H}), 4.60-4.71(\mathrm{~m}, 2 \mathrm{H}), 4.77-4.87(\mathrm{~m}, 2 \mathrm{H}), 5.20(\mathrm{~m}, 1 \mathrm{H}), 5.30(\mathrm{~m}, 1 \mathrm{H})$, $5.62(\mathrm{~m}, 1 \mathrm{H})$ 7.90-7.93 (m, 1H), 8.01-8.03 (m, 3H), 8.17-8.26 (m, 4H), 8.32-8.34 (m, 1H), 9.49 (s, 1H); ${ }^{13} \mathrm{C}$ NMR (100 MHz, DMSO-d 6 ) $\delta 28.87,33.54,34.52,61.83,69.55,71.92,72.13$, $74.48,76.17,76.81,77.31,79.94,80.63,81.85,91.79,105.01,124.82,125.48,125.58,126.23$, 126.37 , 127.62, 127.93, 128.66, 128.85, 128.97, 129.48, 130.70, 131.77, 132.24, 137.80, 173.69. HRMS: $m / z$ calcd. for $\mathrm{C}_{32} \mathrm{H}_{38} \mathrm{~N}_{2} \mathrm{O}_{11}\left(\mathrm{M}+\mathrm{Na}^{+}\right)$649.2373, found: 649.2371. Anal.: calcd. For $\mathrm{C}_{32} \mathrm{H}_{38} \mathrm{~N}_{2} \mathrm{O}_{11}$ : C 61.33, H 6.11, N 4.47; found: C 61.14, H 6.38, N 4.25. 
Synthesis of PyMal. 4-(pyren-1-yl) butanehydrazide (1 g, $3.47 \mathrm{mmol})$ and D-maltose mono hydrate $(1.6 \mathrm{~g}, 4.20 \mathrm{mmol})$ were taken in the round bottom flask. The mixture was dissolved by adding $35 \mathrm{~mL}$ of $\mathrm{MeOH} / \mathrm{CHCl}_{3}(3: 1 \mathrm{v} / \mathrm{v})$ to it and then stirred under refluxing conditions for $24 \mathrm{~h}$. The resultant mixture was cooled, and the solvent was evaporated in vacuum to furnish a yellowish white residue. The residue so obtained was purified by washing with chloroform followed by water. The resultant residue was vacuum dried to get a yellowish white solid product with $71 \%$ isolated yield. M.P. $\left(168{ }^{\circ} \mathrm{C}\right)$ FT-IR $\left(\mathrm{KBr} \mathrm{cm}^{-1}\right)$ 3415, 3297, 3066, 2870, 1650, 1528, 1457, 1301,1122, 1083; ${ }^{1} \mathrm{H}$ NMR (400 MHz, DMSO-d $) \delta$ 1.98-2.02 (m, 2H), 2.19-2.25 (m, 2H), 3.01-3.07 (m, 3H), 3.23-3.24 (m, 3H), 3.32-3.31 (m, 3H), 3.34-3.36 (m, 2H), 3.43-3.45 (m, 3H), $4.36(\mathrm{~m}, 1 \mathrm{H}), 4.46(\mathrm{~m}, 2 \mathrm{H}), 4.98-4.99(\mathrm{~m}, 3 \mathrm{H}), 8.30(\mathrm{~m}, 1 \mathrm{H}), 5.48$ $(\mathrm{m}, 1 \mathrm{H}), 5.57(\mathrm{~m}, 1 \mathrm{H}), 7.91-7.93(\mathrm{~m}, 1 \mathrm{H}), 8.01-8.10(\mathrm{~m}, 3 \mathrm{H}), 8.19-8.26(\mathrm{~m}, 4 \mathrm{H}), 8.32-8.34(\mathrm{~m}$, $1 \mathrm{H}), 9.48(\mathrm{~s}, 1 \mathrm{H}) ;{ }^{13} \mathrm{C}$ NMR (100 MHz, DMSO-d 6 ) $\delta 28.41,33.11,33.87,61.79,70.85,71.52$, $73.43,74.25,74.47,77.24,77.32,79.75,80.82,81.10,91.70,101.96,124.42,125.10,125.18$, $125.77,125.90,127.10,127.48,128.26,128.41,128.51,129.10,130.28,131.38,131.84$, 137.34, 172.98. HRMS: $m / z$ calcd. for $\mathrm{C}_{32} \mathrm{H}_{38} \mathrm{~N}_{2} \mathrm{O}_{11}\left(\mathrm{M}+\mathrm{Na}^{+}\right)$627.2554, found: 627.2554. Anal.: calcd. For $\mathrm{C}_{32} \mathrm{H}_{38} \mathrm{~N}_{2} \mathrm{O}_{11}$ : C 61.33, H 6.11, N 4.47; found: C 61.48, H 6.53, N 4.10.

\section{References:}

Sa. M. R. Molla and S. Ghosh, Chem. Eur. J., 2012, 18, 9860-9869.

Sb. S. Akama, T. Makia and M. Yamanaka, Chem. Commun., 2018, 54, 8814-8817.

Sc. P. Rajamalli, P. S. Sheeta and E. Prasad, Chem. Commun., 2013, 49, 6758-6760. 


\section{Characterization of PyLac.}

\section{Mass spectrum}

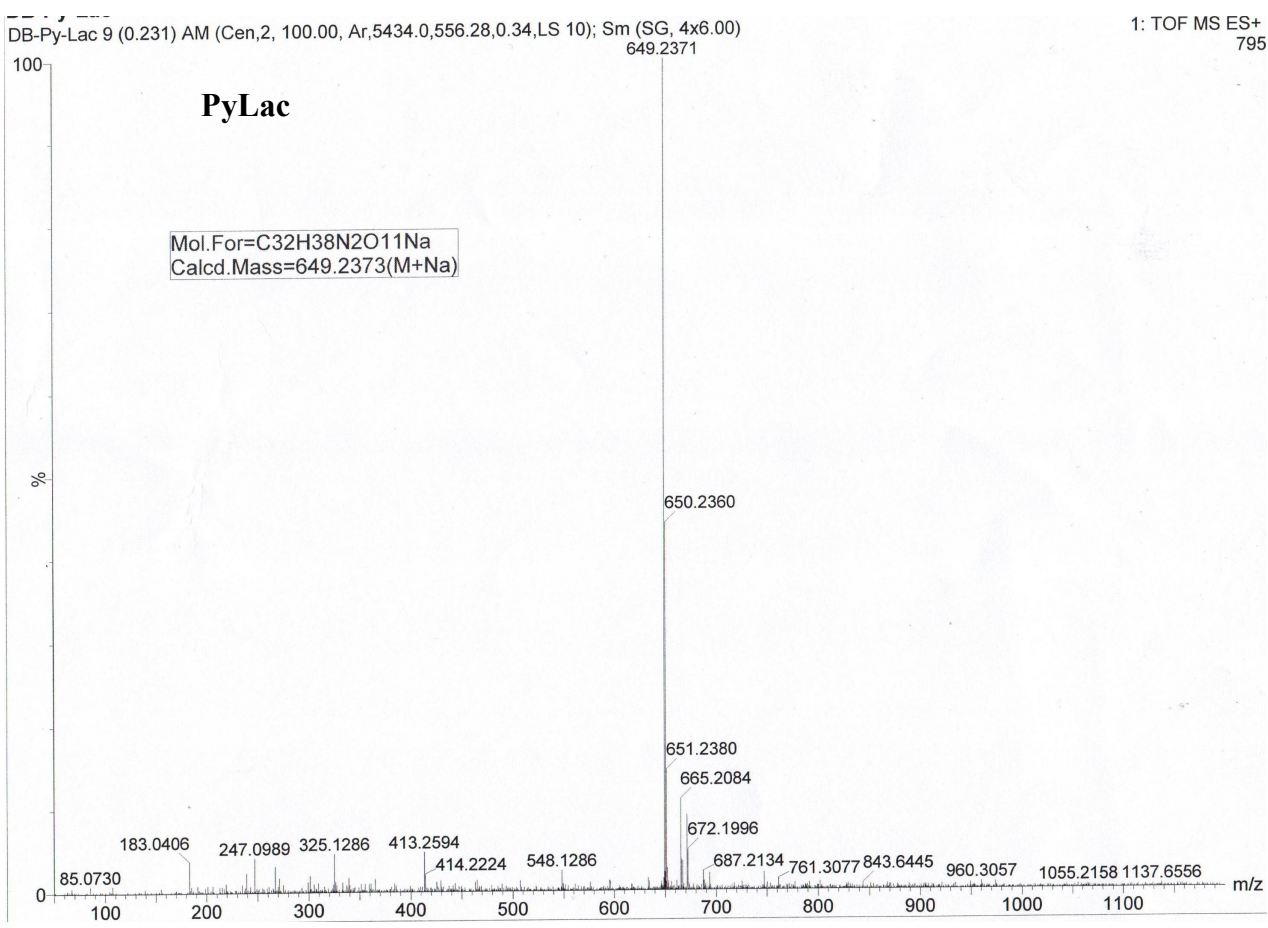

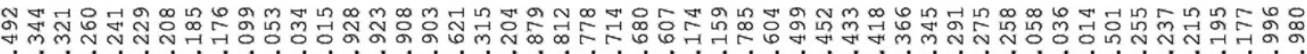

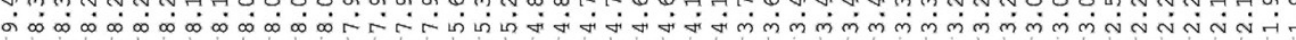

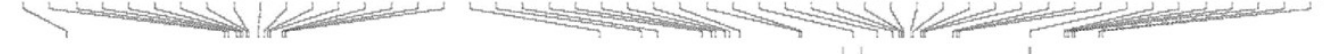

PyLac

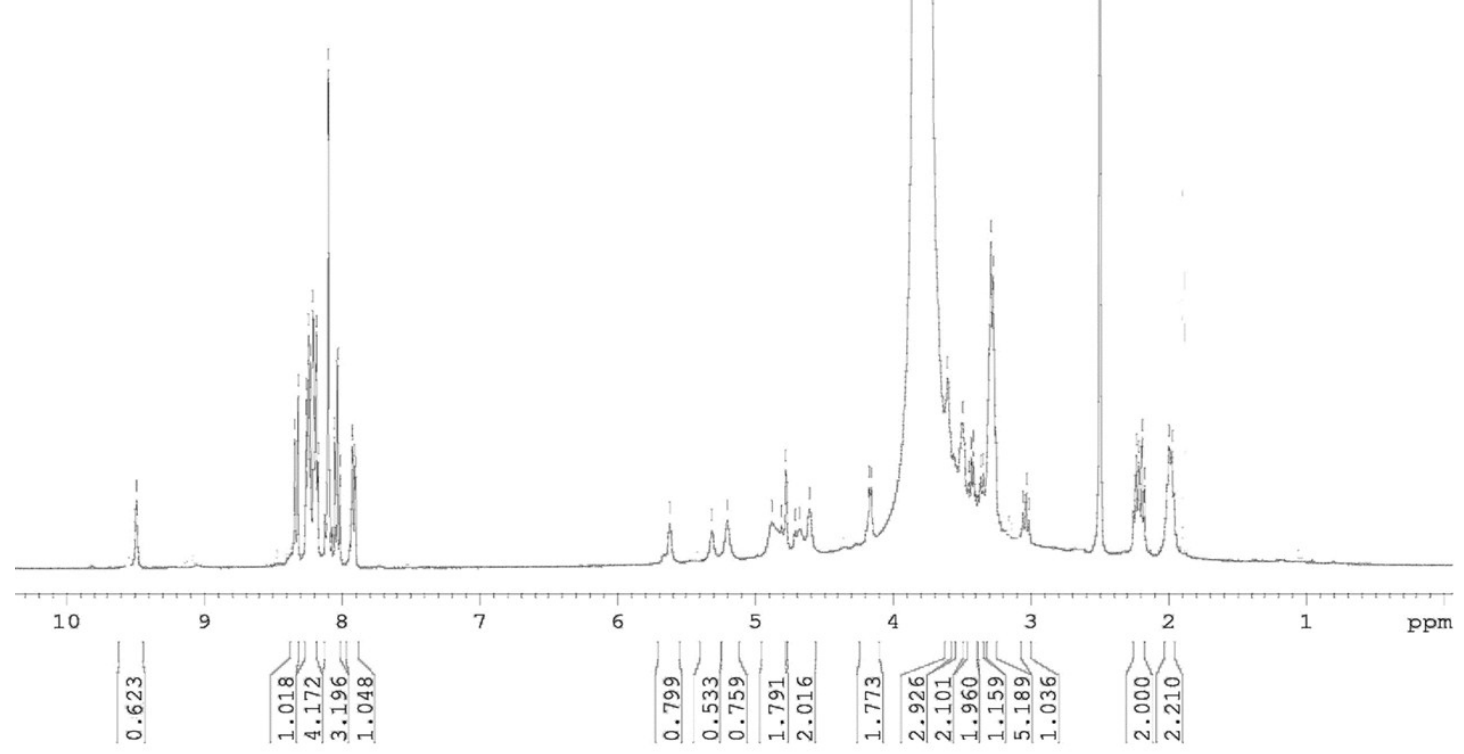

${ }^{1} \mathrm{H}$ NMR 


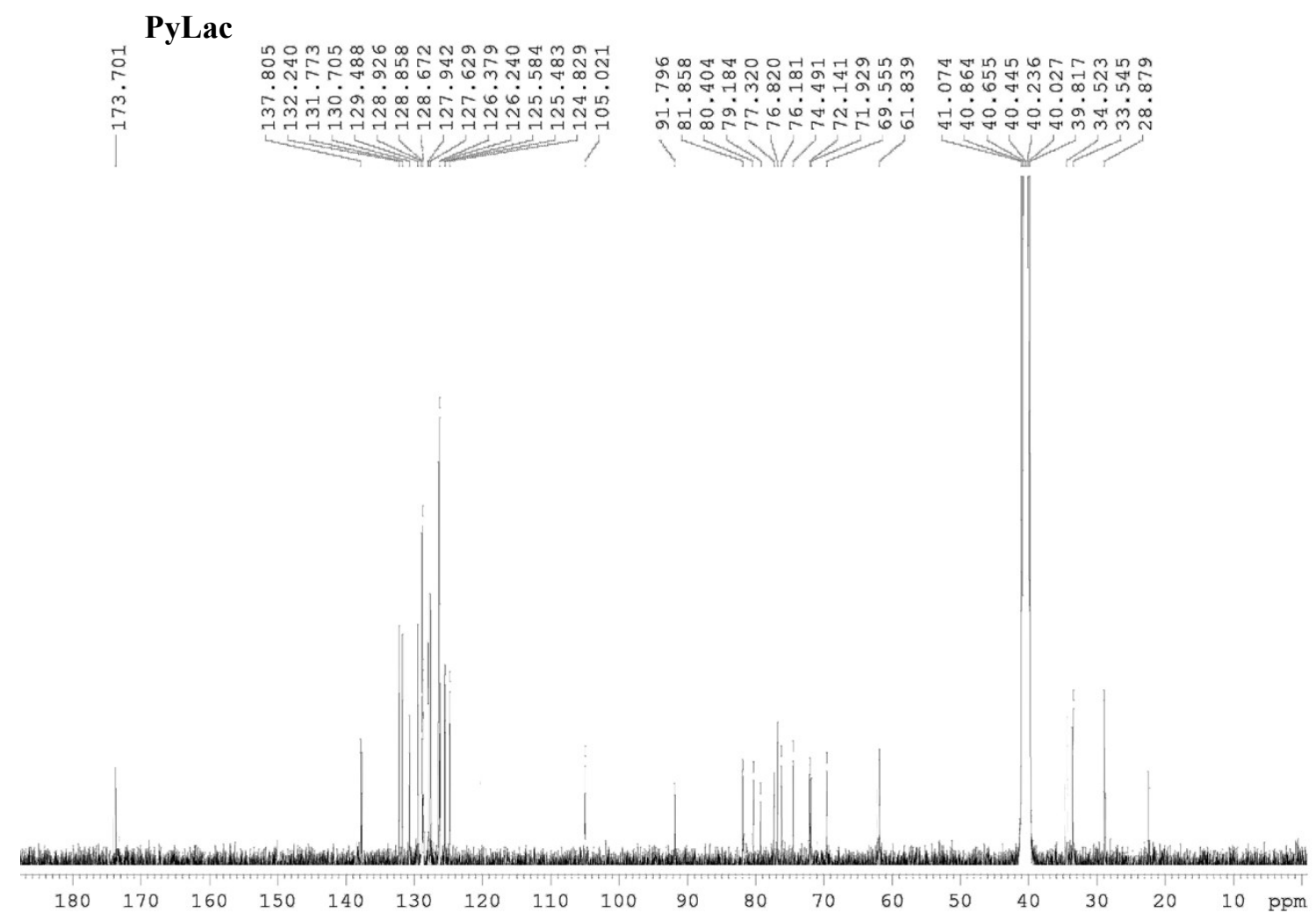

${ }^{13} \mathrm{C}$ NMR

\section{Characterization of PyMal}




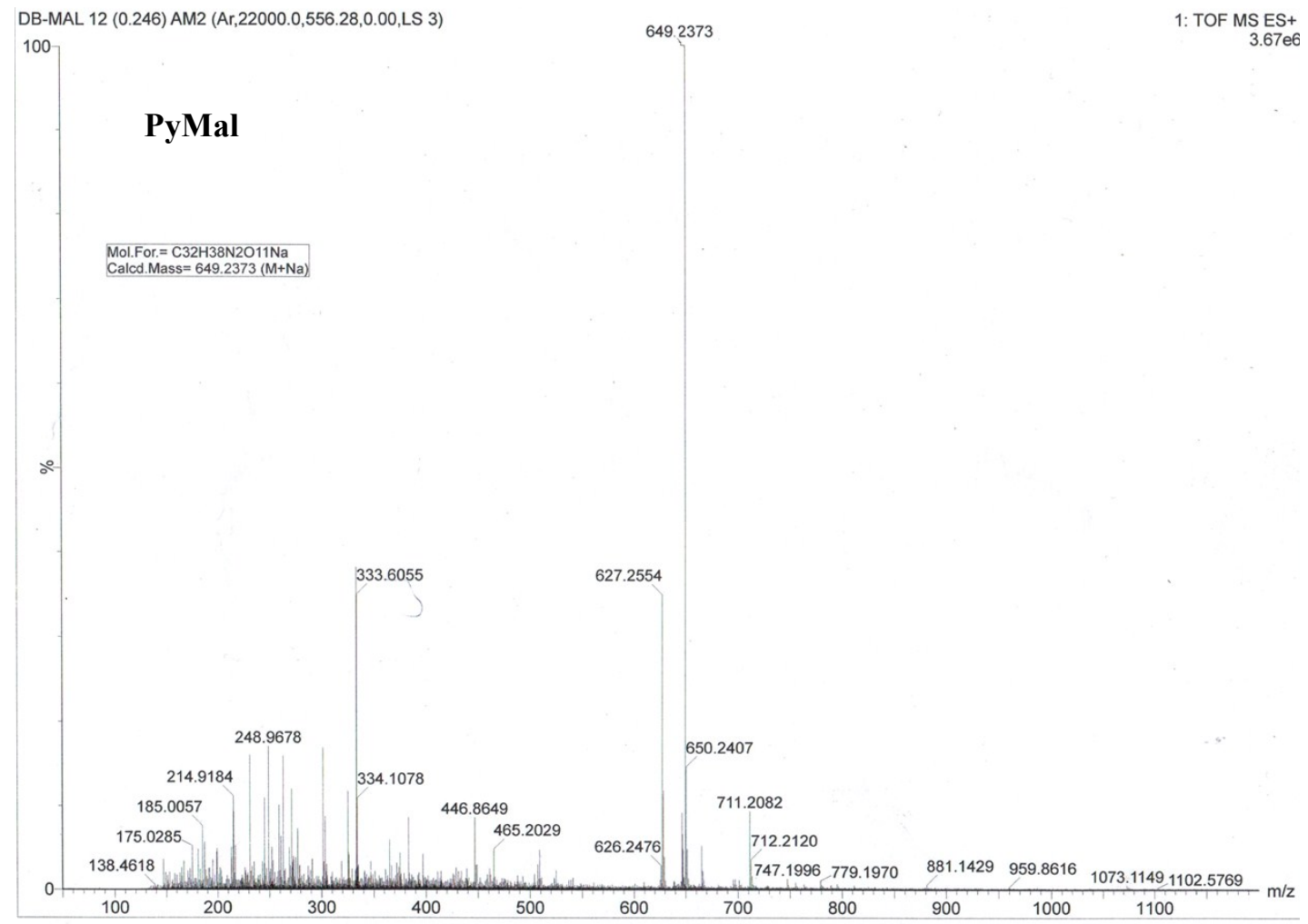

Mass spectrum

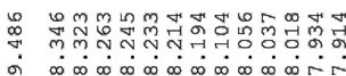

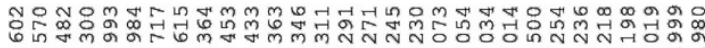

மं மं

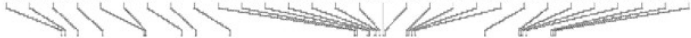

PyMal
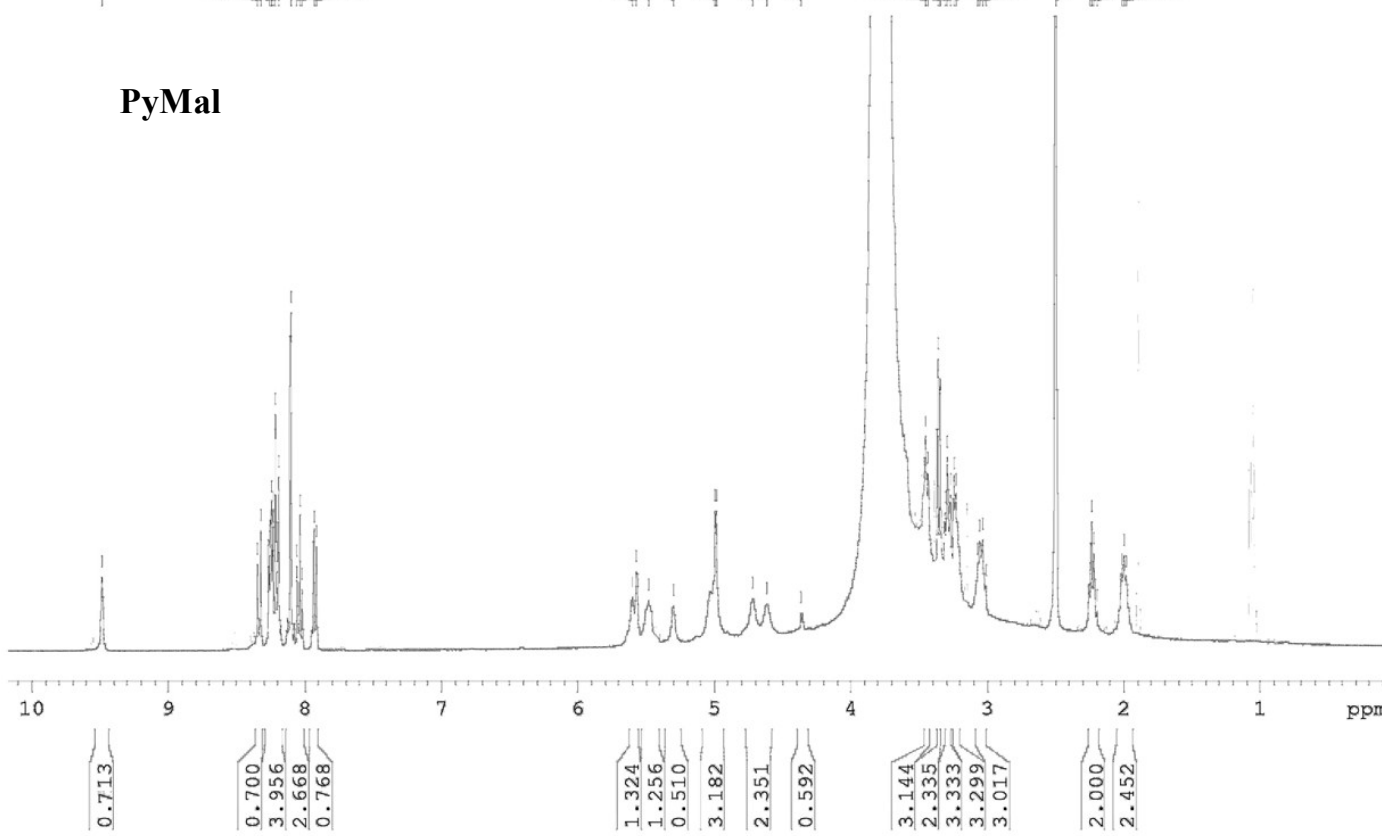

${ }^{1} \mathrm{H}$ NMR
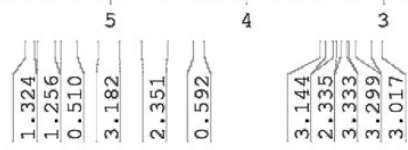

ํ.

\section{${ }^{1} \mathrm{H}$ NMR}




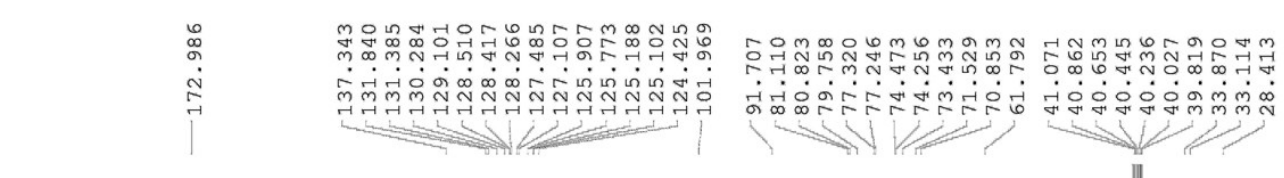

PyMal

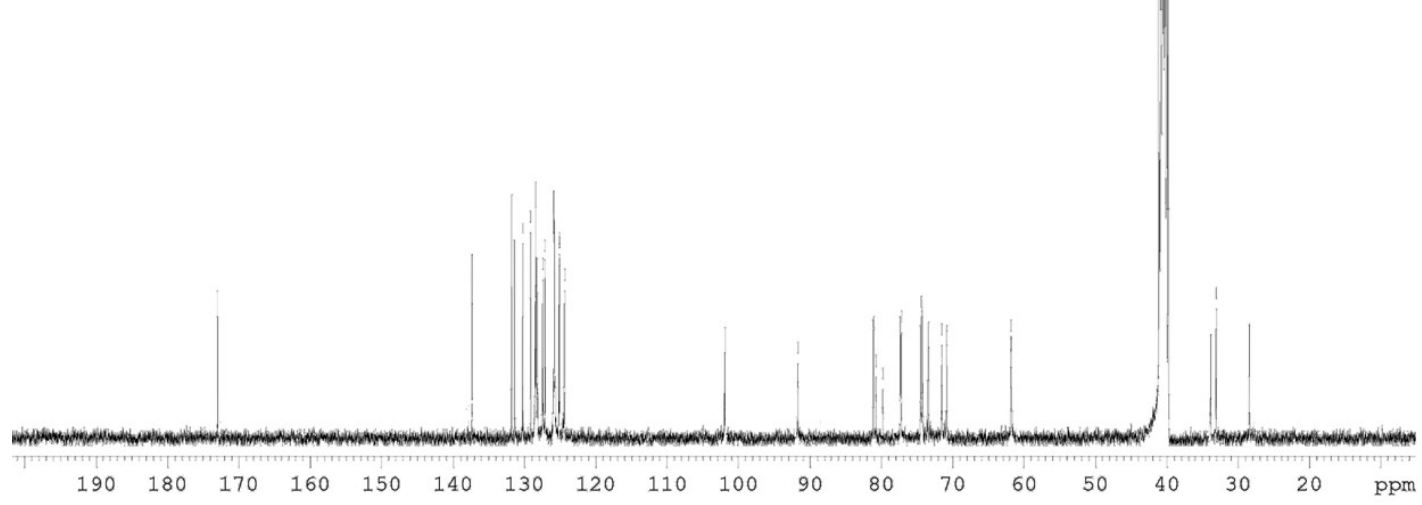

${ }^{13} \mathrm{C}$ NMR

\begin{tabular}{|c|c|c|c|c|}
\hline System Used & Medium & Detection limit & Application & Ref \\
\hline $\begin{array}{l}\text { Lactose-stabilized } \\
\text { gold nanoparticles }\end{array}$ & $\begin{array}{c}\text { Tris buffer } \\
\text { solution }(10 \mathrm{mM} \text {, } \\
\mathrm{pH} \\
7.6)\end{array}$ & $54 \mathrm{nM}$ & $\begin{array}{l}\mathrm{CT} \text { in electrolyte } \\
\text { solutions that } \\
\text { mimic the watery } \\
\text { stool of cholera } \\
\text { patients }\end{array}$ & $\begin{array}{c}\text { Anal. } \\
\text { Chem., } \\
\text { 2007, 79, } \\
1356-1361 .\end{array}$ \\
\hline $\begin{array}{l}\text { Antibody-conjugated } \\
\text { gold nanoparticle }\end{array}$ & Water & $10 \mathrm{nM}$ & $\begin{array}{l}\text { Cholera toxin } \\
\text { detection in local } \\
\text { lake water }\end{array}$ & $\begin{array}{c}\text { Anal. Chim. } \\
\text { Acta, 2015, } \\
\mathbf{8 9 2}, 167- \\
174\end{array}$ \\
\hline $\begin{array}{l}\text { Tetraphenylethylene } \\
\text { (TPE)- } \\
\text { based glycoconjugates }\end{array}$ & $\begin{array}{l}50 \text { mm PBS } \\
\text { solution, } \\
\text { pH } 7.3\end{array}$ & - & - & $\begin{array}{l}\text { Chem. } \\
\text { Asian J., } \\
2011, \mathbf{6},\end{array}$ \\
\hline
\end{tabular}




\begin{tabular}{cccc}
\hline & & & $2376-2381$ \\
\hline $\begin{array}{c}\text { Lactose based } \\
\text { hydrogel* }\end{array}$ & Pure Water & Detection in & Present \\
& water stool & work \\
& sample, different & \\
& water sample, & \\
& Paper strips- & \\
& based detection, & \\
& Gel-to-sol & \\
& transition & \\
\hline
\end{tabular}

* This is the first report for the detection of CT in the hydrogel system.

Table S1. Comparison table of detection limits by different material including present work. 

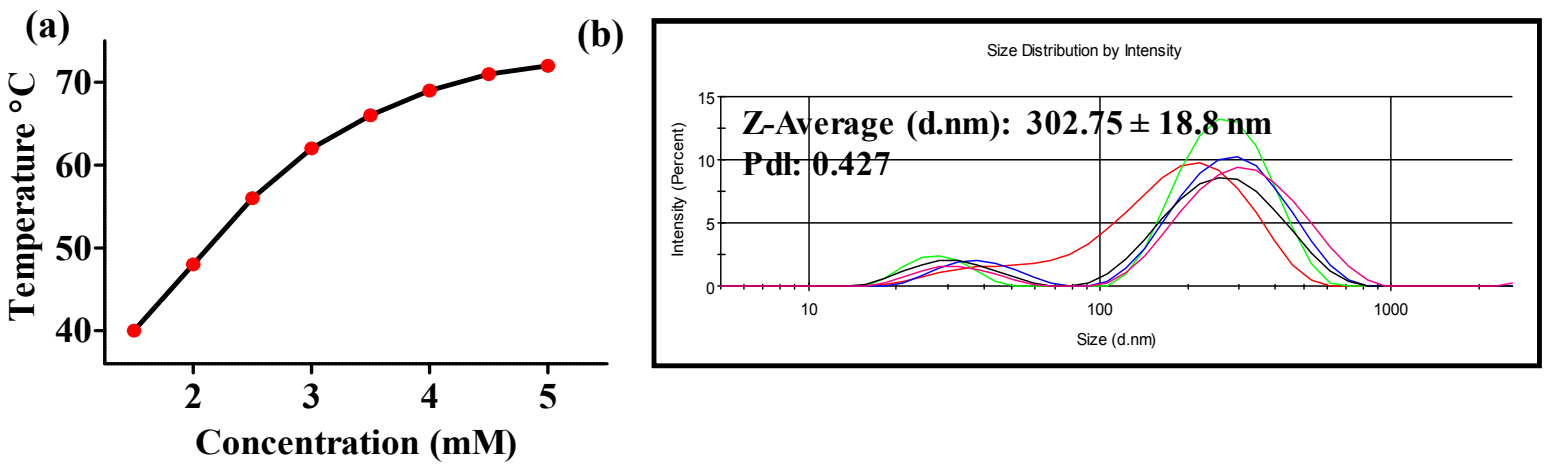

Figure S1. (a) Concentration dependent gel melting temperature ( $\left.T_{g e l}\right)$ of PyLac. (b) Measurements of an average hydrodynamic diameter $\left(D_{h}\right)$ of the solution of PyLac $(0.09 \mathrm{mM})$ in water.
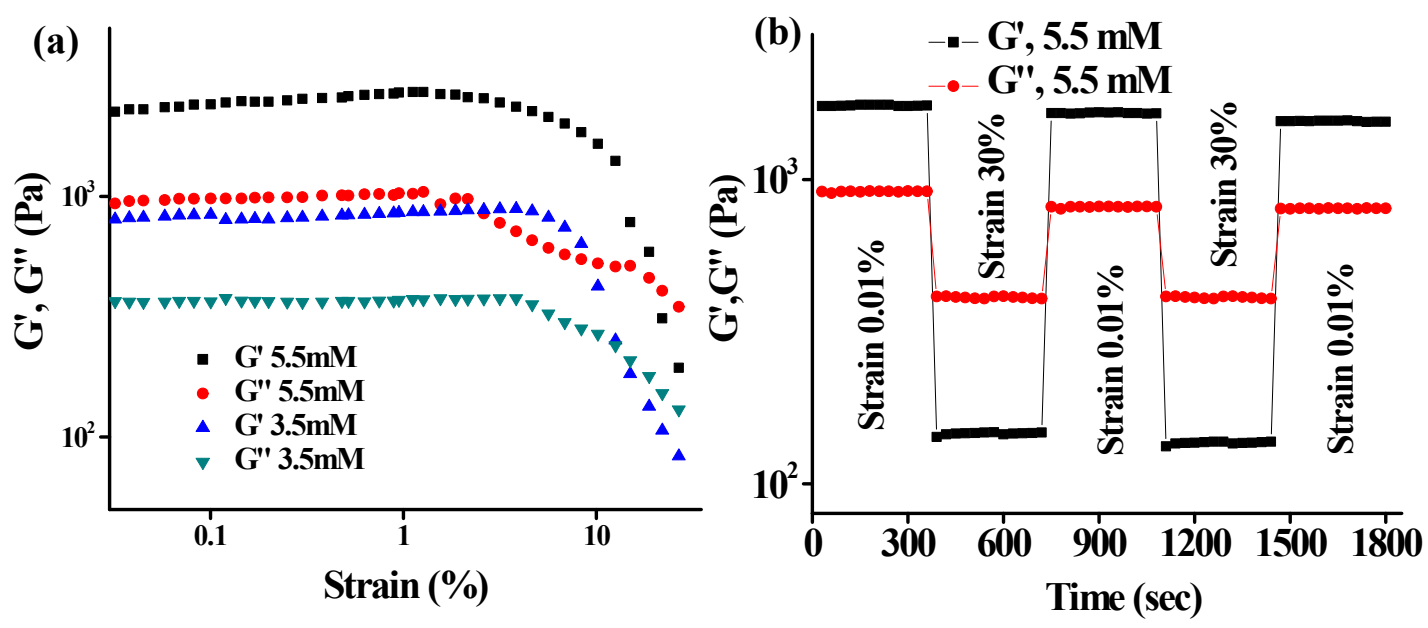

Figure S2. (a) Concentration dependent oscillatory amplitude sweep rheology data of PyLac (3.5 and $5.5 \mathrm{mM}$ ). (b) Hysteresis Loop test rheology data of PyLac (5.5 mM). 

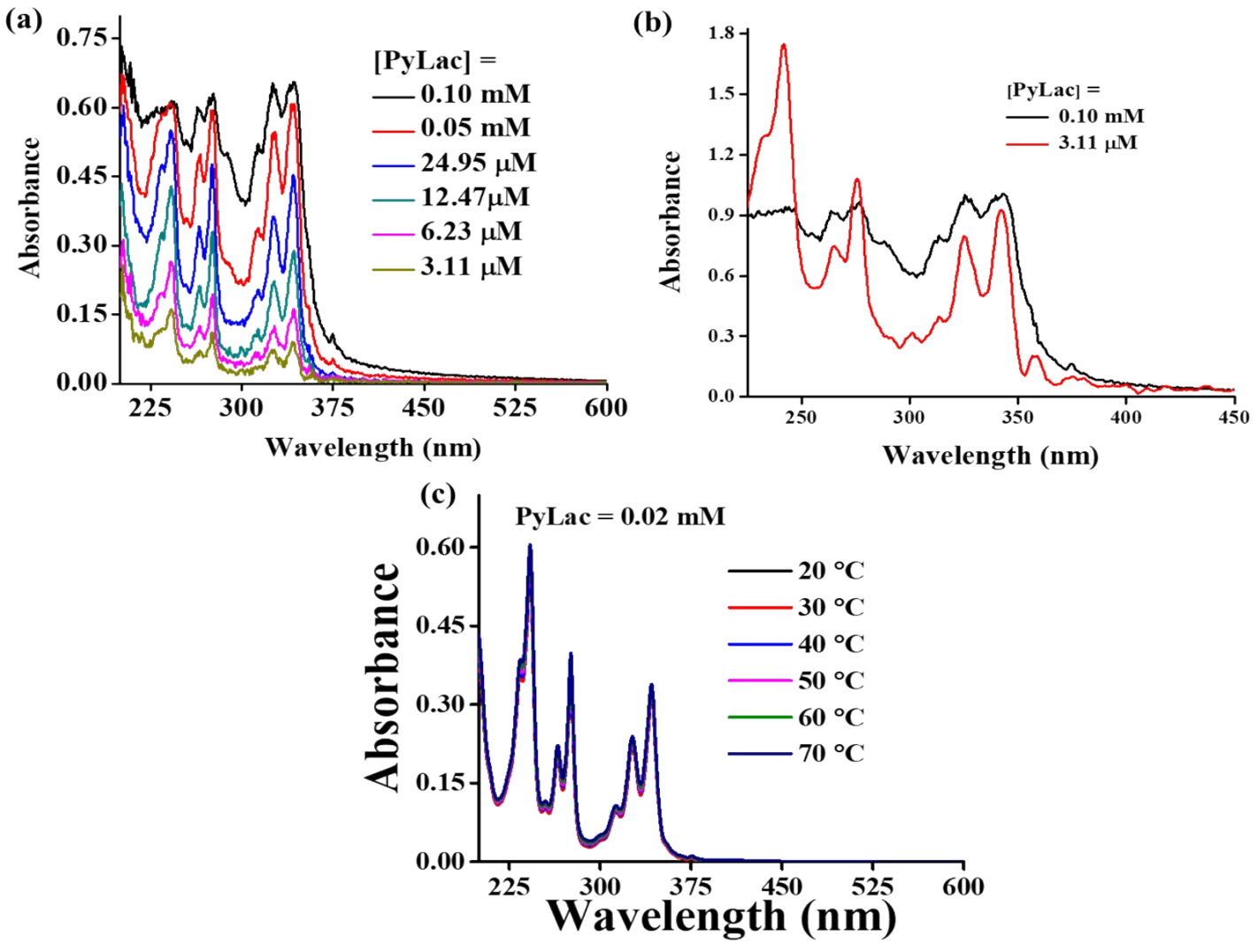

Figure S3. (a) Variable concentration absorption spectra of PyLac. (b) Absorbance plot of PyLac at low $(3.11 \mu \mathrm{M})$ vs. high $(0.10 \mathrm{mM})$ concentration in water. (c) Temperature dependent absorption spectra of PyLac (0.02 mM)

(a)

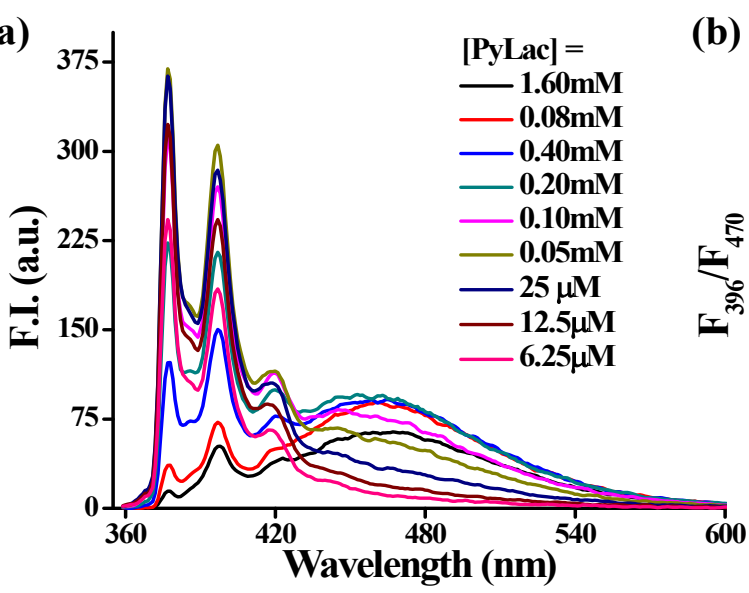

(b) 20

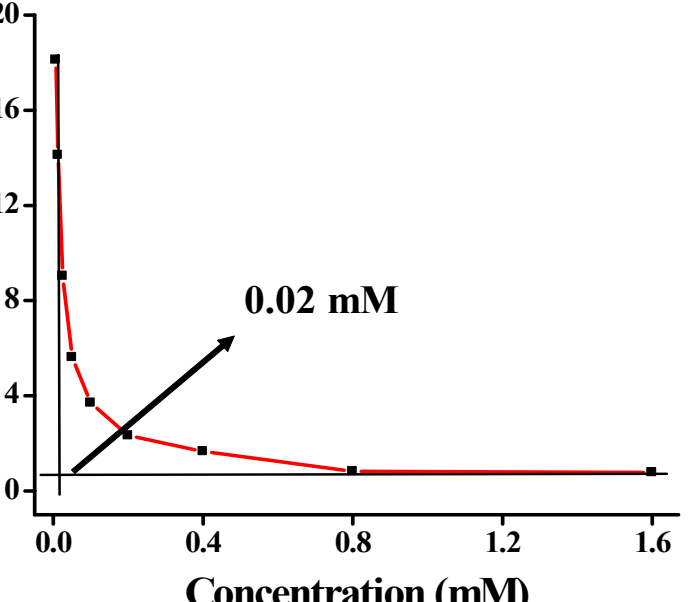

Concentration (mM)

Figure S4. (a) Variable concentration emission spectra $\left(\lambda_{\text {ex }}=345 \mathrm{~nm}\right)$ of PyLac $(6.25 \mu \mathrm{M}-1.60 \mathrm{mM})$ in water. (b) Plot of relative intensities of monomer/excimer $\left(\mathrm{F}_{396} / \mathrm{F}_{470}\right)$ band versus concentration of PyLac $(6.25 \mu \mathrm{M}-1.60 \mathrm{mM})$. 
(a)

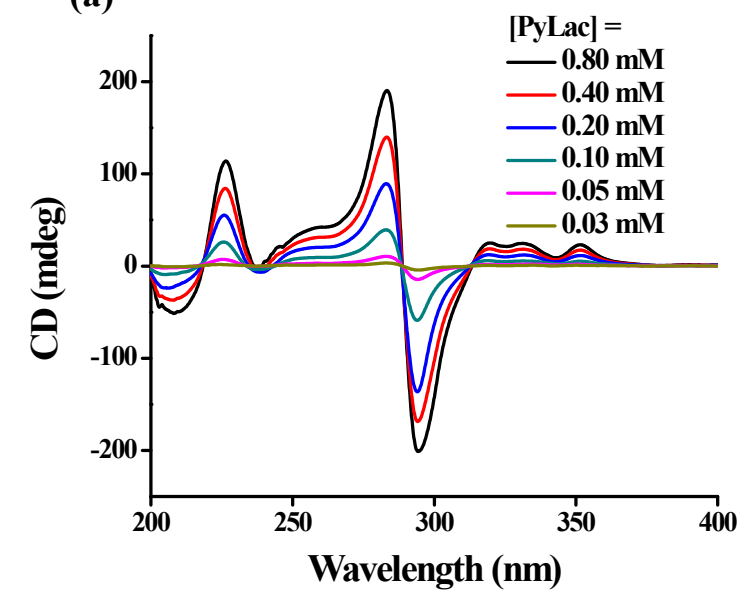

(b)

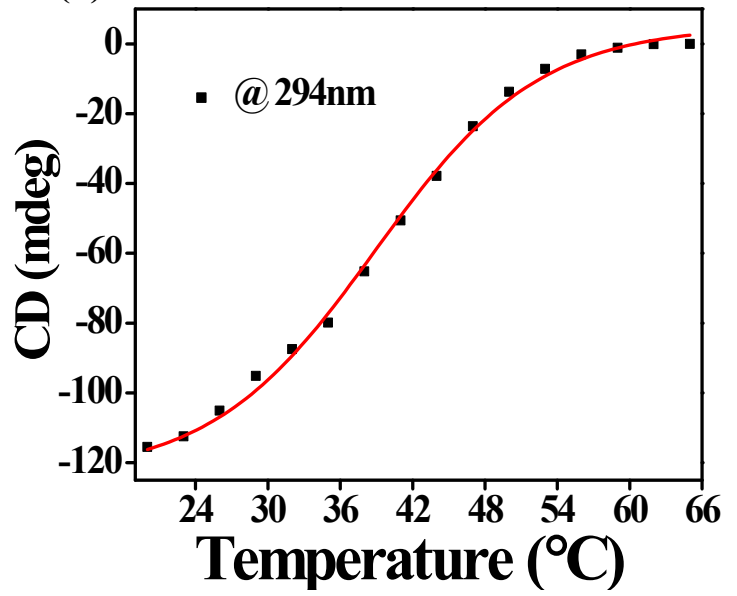

Figure S5. (a) Variable concentration CD spectra of PyLac $(0.03 \mathrm{mM}-0.80 \mathrm{mM})$ in water. (b) Plot of CD signal vs. temperature of PyLac $(0.20 \mathrm{mM})$ in water.

(a)

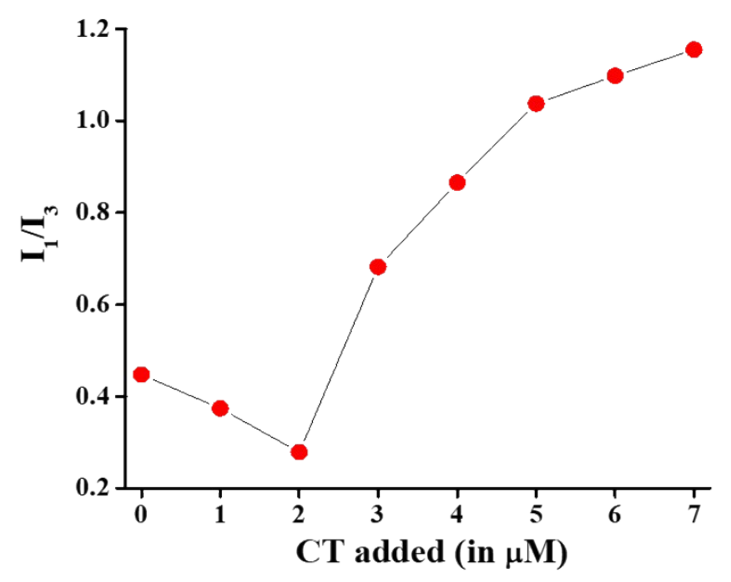

(b)

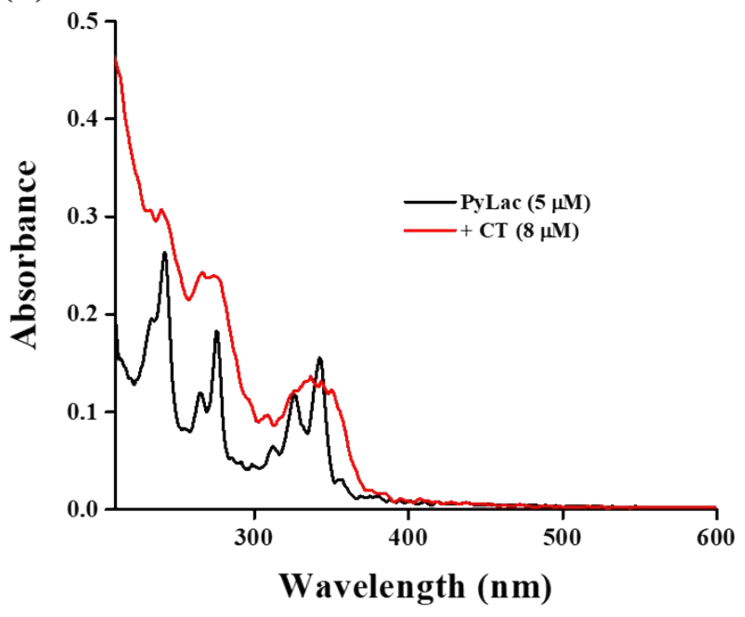

Figure S6. (a) Changes in $\mathrm{I}_{1} / \mathrm{I}_{3}$ ratio of PyLac $\left(5 \mu \mathrm{M}, \lambda_{\mathrm{ex}}=345 \mathrm{~nm}\right)$ on addition of increasing $\mathrm{CT}(0-7$ $\mu \mathrm{M})$ concentration. (b) Absorbance spectra of PyLac $(5 \mu \mathrm{M})$ in the presence of CT ( $8 \mu \mathrm{M})$ in water. 
(a)

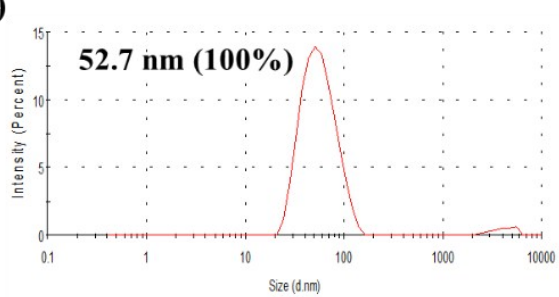

(b)

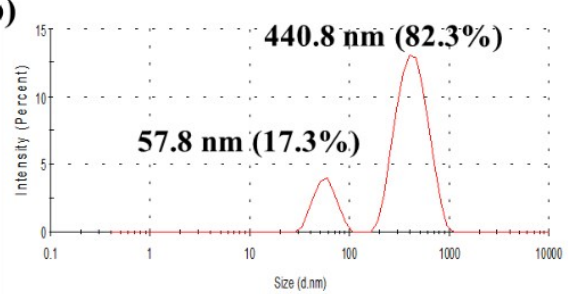

(c)

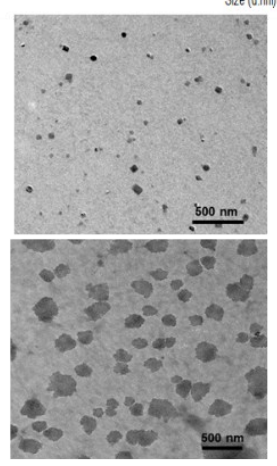

(e)

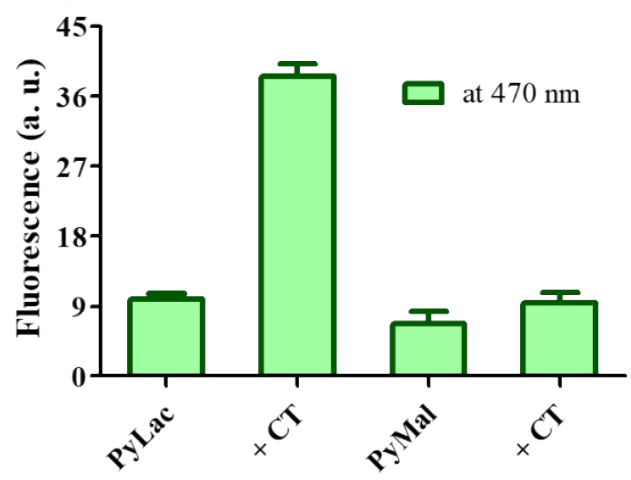

Figure S7. Hydrodynamic diameter of (a) PyLac $(5 \mu \mathrm{M})$ alone, (b) PyLac $(5 \mu \mathrm{M})$ in the presence of CT $(8 \mu \mathrm{M})$ in water. TEM images of (c) PyLac $(5 \mu \mathrm{M})$, (d) PyLac $(5 \mu \mathrm{M})$ in the presence of CT $(8$ $\mu \mathrm{M})$. (e) Interaction of PyLac $\left(5 \mu \mathrm{M}, \lambda_{\mathrm{ex}}=345 \mathrm{~nm}\right)$ and PyMal $\left(5 \mu \mathrm{M}, \lambda_{\mathrm{ex}}=345 \mathrm{~nm}\right)$ with CT $(8 \mu \mathrm{M})$ in water (number of independent experiments: 2 ).

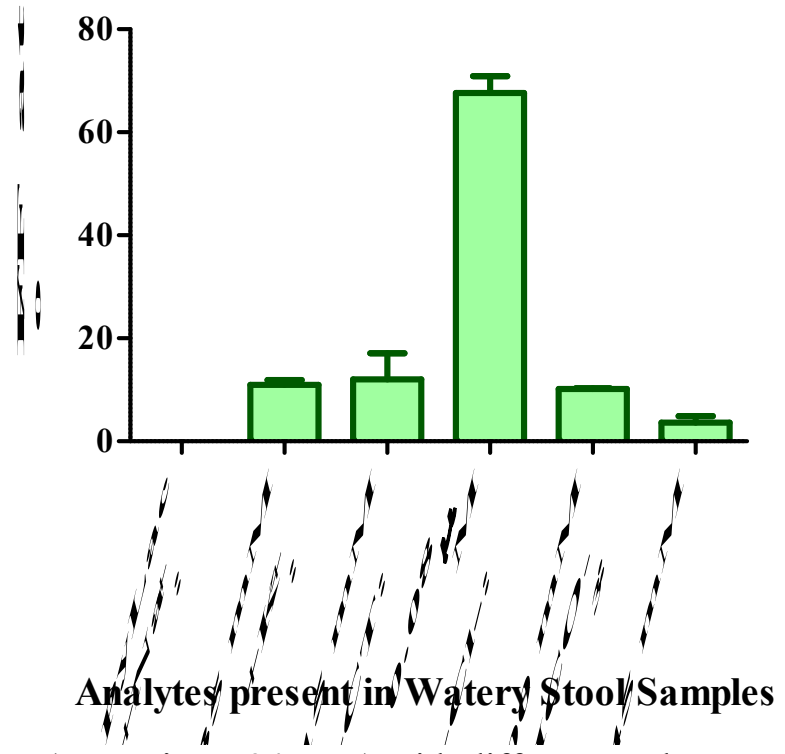

Figure S8. Interaction of PyLac ( $5 \mu \mathrm{M}, \lambda_{\mathrm{ex}}=345 \mathrm{~nm}$ ) with different analyte present in stool samples (number of independent experiments: 2). 
(a)

\begin{tabular}{|c|c|c|c|c|}
\hline & $\begin{array}{c}\text { CT }(\mu \mathrm{M}) \\
\text { Added }\end{array}$ & $\mathbf{F}_{0} / \mathbf{F}$ & $\begin{array}{c}\text { CT }(\mu \mathrm{M}) \\
\text { Calcd. }\end{array}$ & $\begin{array}{c}\text { Difference } \\
(\%)\end{array}$ \\
\hline \multirow{4}{*}{$\begin{array}{c}\text { Tap } \\
\text { water }\end{array}$} & 1 & 1.22 & 0.91 & 9.0 \\
\hline & 2 & 1.52 & 1.87 & 6.5 \\
\hline & 3 & 2.17 & 3.28 & 9.3 \\
\hline & 4 & 2.83 & 4.91 & 2.3 \\
\hline \multirow{4}{*}{$\begin{array}{c}\text { Pool } \\
\text { water }\end{array}$} & 1 & 1.27 & 1.04 & 4.0 \\
\hline & 2 & 1.42 & 1.73 & 1.4 \\
\hline & 3 & 2.11 & 3.13 & 4.3 \\
\hline & 4 & 3.15 & 4.21 & 5.2 \\
\hline \multirow{4}{*}{$\begin{array}{c}\text { Sea } \\
\text { water }\end{array}$} & 1 & 1.13 & 0.93 & 7.0 \\
\hline & 2 & 1.32 & 1.77 & 1.2 \\
\hline & 3 & 1.81 & 3.19 & 6.3 \\
\hline & 4 & 2.40 & 3.85 & 3.8 \\
\hline
\end{tabular}

(b)
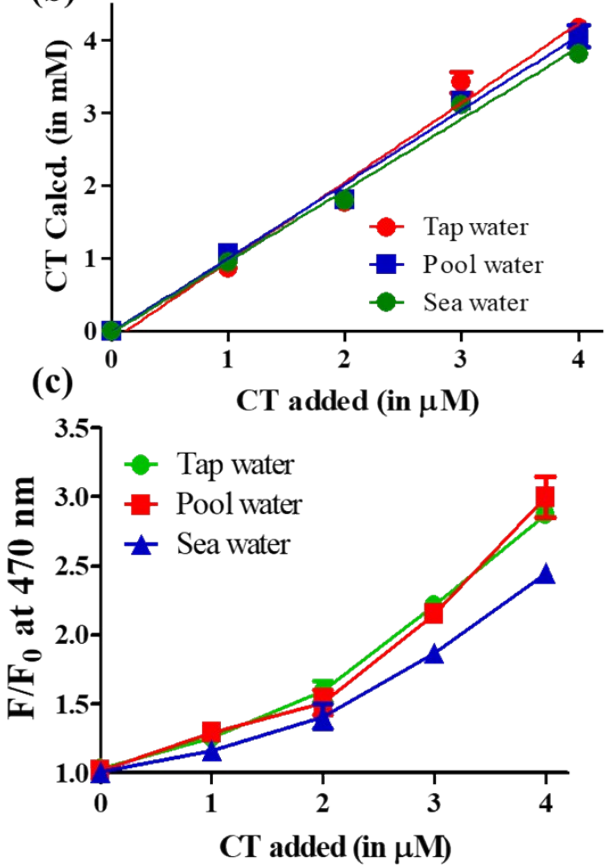

Figure S9. (a) Quantitative estimation of CT using PyLac (5 $\mu \mathrm{M})$ in different water sample (number of independent experiments: 2). (b) Recovery plot of PyLac (5 $\mu \mathrm{M}, \lambda_{\mathrm{ex}}=345 \mathrm{~nm}$ ) upon interaction of with CT in different water samples (number of independent experiments: 2). (c) Change in the emission intensity of PyLac $(5 \mu \mathrm{M}, \lambda \mathrm{ex}=345 \mathrm{~nm})$ upon interaction of with $\mathrm{CT}$ in different water samples (number of independent experiments: 2). 


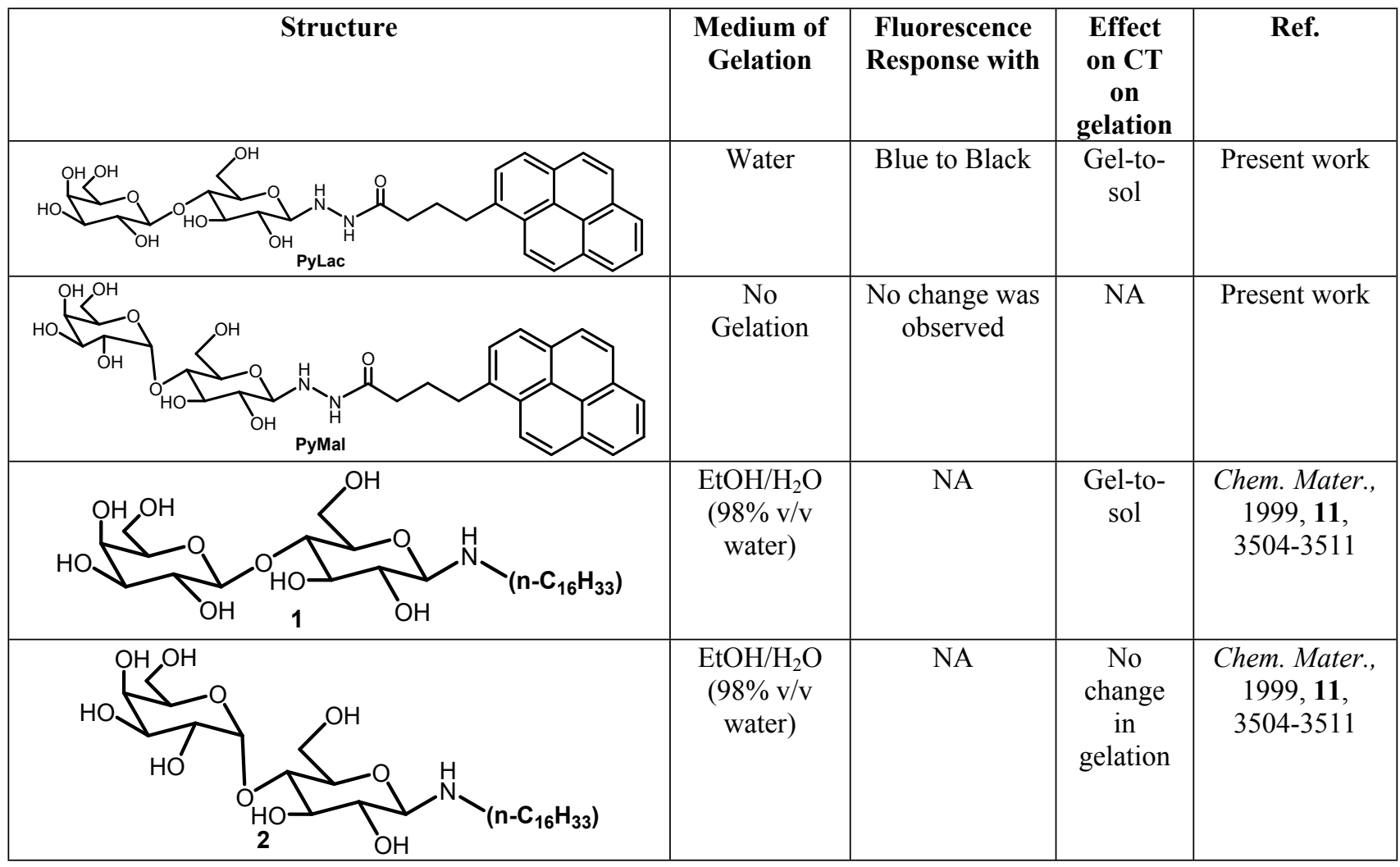

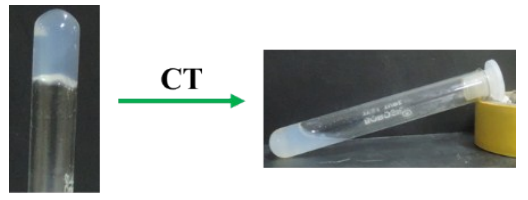

1

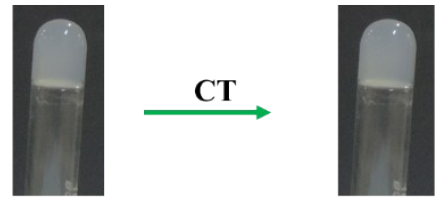

2

Table S2. Table shows the comparison of different hydrogel on interaction with CT. 